\title{
Effects of Prehospital Traige and Diagnosis of ST Segment Elevation Myocardial Infarction on Mortality Rate
}

This article was published in the following Dove Press journal: International Journal of General Medicine

\author{
Reza Alizadeh $\mathbb{D}^{\prime}$ \\ Ziba Aghsaeifard ${ }^{2}$ \\ Mostafa Sadeghi ${ }^{3}$ \\ Parisa Hassani ${ }^{4}$ \\ Peyman Saberian ${ }^{3}$ \\ 'Department of Anesthesiology and \\ Intensive Care, Faculty of Medicine, AJA \\ University of Medical Sciences, Tehran, \\ Iran; ${ }^{2}$ Department of Internal Medicine, \\ School of Medicine, Sina Hospital, Tehran \\ University of Medical Sciences, Tehran, \\ Iran; ${ }^{3}$ Department of Anesthesiology, \\ School of Medicine, Imam Khomeini \\ Hospital, Tehran University of Medical \\ Sciences, Tehran, Iran; ${ }^{4}$ School of \\ Medicine, Imam Khomeini Hospital, \\ Tehran University of Medical Sciences, \\ Tehran, Iran
}

Correspondence: Peyman Saberian Department of Anesthesiology, Tehran University of Medical Sciences, Tehran, Iran

Email md.saberian.p@gmail.com
Introduction: Adverse outcomes and mortality associated with STEMI (ST segment elevation myocardial infarction) are associated with the management and diagnosis time. The aim of this study is to evaluate the outcomes of prehospital diagnosis of STEMI via emergency medical service (EMS) on mortality, in comparison to the patients who did not receive EMS. Methods: This retrospective study included STEMI patients, who underwent primary angioplasty. The patients were categorized as group A: referred without emergency service, group B: patients who did not receive PPCI and group C: patients referred via ambulance and received telecardiology. Medical records of these patients were evaluated for the diagnosis time, door-to-balloon time, in-hospital, six months, one year and three-year mortality, left ventricular ejection fraction and previous history of cardiovascular conditions and surgeries. The data were recorded and statistically analyzed using SPSS v21.

Results: Of 424 patients studied, 79 were referred without emergency service (group A), 52 patients did not receive PPCI (group B) and 293 patients were referred via ambulance with telecardiology (group C). Door-to-balloon time was least in group C (57.78 min) compared to group A (141.70 min). In-hospital, six months, one year and three-year mortality was least in group $\mathrm{C}$, however, the difference was not statistically significant. The left ventricular ejection fraction was significantly greater in group $\mathrm{C}$.

Conclusion: The results of our study indicate that prehospital diagnosis and telecardiology significantly reduce door-to-balloon time in STEMI patients referred for percutaneous intervention and might have an influence on short-term and long-term mortality rates.

Keywords: prehospital, mortality rates, cardiology, myocardial infarction, STEMI

\section{Introduction}

Myocardial infarction is one of the leading causes of morbidity and mortality globally and adds significantly to health and economic burdens. Early management of acute STEMI (ST segment elevation myocardial infarction) can reduce ischemic time duration, morbidity and mortality. ${ }^{1}$ Over the past few years, management of STEMI has significantly reduced the mortality rate. Nonetheless, the long-term mortality rate still remains significant. ${ }^{2}$

The time to re-establish blood flow (reperfusion) is closely related to the morbidity and mortality of STEMI patients and is the primary goal of the treatment. The incidence of adverse events during myocardial ischemia with a delay in reperfusion over $30 \mathrm{~min}$ is associated with a $7.5 \%$ increase in mortality. ${ }^{7}$ Other factors associated with increased in-hospital mortality also include greater 
SYNTAX score (evaluation of clinical variable and coronary anatomy), ${ }^{3}$ Killip-Kimball class III and $\mathrm{IV}^{4,5}$ renal failure, thrombolysis in myocardial infarction (TIMI), PCI $\leq 2$, ejection fraction and some biochemical parameters. ${ }^{6}$ According to the guidelines, PPCI (primary percutaneous coronary intervention) should be performed in less than or equal to $90 \mathrm{~min}$ from the patient's arrival at the hospital, which is known as door-to-balloon time. ${ }^{7}$ Door-to-balloon time can, therefore, chiefly influence mortality in STEMI patients. ${ }^{8,9}$ To achieve this goal, many interventions have been made to increase the speed of reperfusion treatment. The prehospital phase is critical in minimizing the time delay of first medical contact with the EMS (emergency medical service). Two important aspects in this phase are rapid STEMI detection and transfer time to PCI centers. ${ }^{10}$ Ambulances are equipped with a 12-lead ECG (electrocardiography) system that allows trained paramedics to make prompt diagnosis of STEMI and immediate transfer to PCI facilities. Performing 12-lead ECG at this stage is recommended by the Heart Association/American Cardiology College and Canadian Cardiovascular Association. ${ }^{7,11,12}$ A number of studies have suggested that these interventions can reduce mortality among STEMI patients. ${ }^{13}$

The aim of this study is to evaluate short-term and long-term mortality rate among patients who were provided with prehospital EMS, including STEMI diagnosis, compared to those who were not referred to our PCI center via the EMS.

\section{Methods}

This retrospective study was conducted at Imam Khomeini Hospital, where STEMI patients who underwent primary angioplasty were included. These patients were transferred to the hospitals via EMS and their hospital records were evaluated for demographic information (age and sex) and clinical information such as medical history, history of heart attack and stroke, previous history of angioplasty or heart surgery, smoking, and usage of diuretics. In addition, clinical and paraclinical symptoms of patients, including coronary arteries under angioplasty and involvement, cardiac biomarkers, creatinine levels, blood pressure, heart rate, venous congestion and ECG information, and type of myocardial infarction and respiratory arrest before PPCI were recorded. The questionnaire comprised ofinformation regarding the time of the onset of symptoms, the time of the first contact with the medical team, the time of admission of the patient in the Cath Lab, or the time of admission of patient in the hospital (admission time) and duration of PPCI. The final outcome-based section of the questionnaire comprised of the outcomes such as left ventricular dysfunction after angioplasty, postoperative arterial occlusion, hospital mortality, and one-month mortality based on TIMI (thrombosis in myocardial infarction) score and six-month mortality based on GRACE rating.

Prehospital emergency registration time was also noted by the means of GPS (global positioning system).

Exclusion criteria included patients with comorbidities, duration of symptoms and angioplasty greater than $12 \mathrm{~h}$, patients with normal vascular angiography after the surgery in whom PPCI was not performed, absence of medical records of the patients, patients presented with other life-threatening disease, normal-ECG, patients admitted to intensive care unit and those transferred to another hospital, following PPCI.

The outcomes from the questionnaire were computerized and analyzed using R software.

The Kruskal-Wallis test was used to compare variables. Fisher's exact test was also used to compare the percentage (frequency) of qualitative variables. A $p$-value $<0.05$ was considered to be statistically significant.

\section{Results}

The patients were divided into three groups: referral to emergency without (group A, n=79), patients who did not receive PPCI (group $\mathrm{B}, \mathrm{n}=52$ ) and patients referred via ambulance and received telecardiology (group C, n=293).

The three groups did not differ in terms of age and gender, $p=0.089$ and $p=0.3$. The history of previous angioplasty was significantly different among the three groups, $p=0.016$. In addition, bypass surgery of left circumflex artery $p=0.016$, obtuse marginal $p=0.029$, posterior descending artery, right coronary artery, left anterior descending artery and three diseased vessels $p<0.001$, respectively, also differed significantly among the three groups, Table 1 .

During the hospital admission, the three groups did not differ in the mortality rate, $p=0.4$. The six-month, one, and three-year mortality rates were not significantly different in these groups, $p=0.2, p=0.13$ and $p=0.2$. The mean and standard deviation of left ventricular ejection fraction (LVEF) is recorded in Table 2. Kruskal-Wallis test showed that LVEF was significantly higher in group $\mathrm{C}$ compared to group A, $p=0.019$.

According to the Kruskal-Wallis test, the time interval between the onset of symptoms in a STEMI patient and 
Table I Descriptive Statistics Related to Demographic and Clinical Information

\begin{tabular}{|c|c|c|c|c|c|}
\hline Characteristic & $\mathbf{n}$ & $1 / 5, n=293$ & No PCl, $n=52$ & Personal, n=79 & $p$-value \\
\hline Age & 423 & $58.92(12.4 I)$ & 58.85 (I5.9I) & $62.19(12.23)$ & 0.089 \\
\hline Sex & 424 & & & & 0.3 \\
\hline Female & & $51(17 \%)$ & $9(17 \%)$ & $20(25 \%)$ & \\
\hline Male & & $242(83 \%)$ & $43(83 \%)$ & 59 (75\%) & \\
\hline $\mathrm{CHF}$ & 424 & & & & 0.9 \\
\hline Neg & & 285 (97\%) & 51 (98\%) & 78 (99\%) & \\
\hline Pos & & $8(2.7 \%)$ & I (I.9\%) & I (I.3\%) & \\
\hline CAD & 424 & & & & 0.8 \\
\hline Neg & & 289 (99\%) & $52(100 \%)$ & 79 (100\%) & \\
\hline Pos & & $4(1.4 \%)$ & $0(0 \%)$ & $0(0 \%)$ & \\
\hline IHD & 424 & & & & 0.4 \\
\hline Neg & & $238(81 \%)$ & 39 (75\%) & 67 (85\%) & \\
\hline Pos & & 55 (19\%) & $13(25 \%)$ & $12(15 \%)$ & \\
\hline Hypertension & 424 & & & & 0.7 \\
\hline $\mathrm{Neg}$ & & $183(62 \%)$ & $35(67 \%)$ & $52(66 \%)$ & \\
\hline Pos & & $110(38 \%)$ & $17-(33 \%)$ & 27 (34\%) & \\
\hline Diabetes_mellitus & 424 & & & & 0.14 \\
\hline $\mathrm{Neg}$ & & $225(77 \%)$ & $34(65 \%)$ & $55(70 \%)$ & \\
\hline Pos & & $68(23 \%)$ & 18 (35\%) & $24(30 \%)$ & \\
\hline History_of_HLP_and_DLP & 424 & & & & $>0.9$ \\
\hline Neg & & $25 I(86 \%)$ & $45(87 \%)$ & $68(86 \%)$ & \\
\hline Pos & & $42(14 \%)$ & $7(13 \%)$ & II (I4\%) & \\
\hline Chronic_kidney_disease & 424 & & & & 0.5 \\
\hline Neg & & 285 (97\%) & $50(96 \%)$ & 75 (95\%) & \\
\hline Pos & & $8(2.7 \%)$ & $2(3.8 \%)$ & $4(5.1 \%)$ & \\
\hline Cerebral_vascular_disease & 424 & & & & 0.2 \\
\hline Neg & & $292(100 \%)$ & 51 (98\%) & 78 (99\%) & \\
\hline Pos & & I (0.3\%) & I (I.9\%) & I (I.3\%) & \\
\hline Chronic_lung_disease & 424 & & & & 0.060 \\
\hline Neg & & $283(97 \%)$ & 48 (92\%) & 72 (9l\%) & \\
\hline Pos & & $10(3.4 \%)$ & $4(7.7 \%)$ & 7 (8.9\%) & \\
\hline Previous_stroke & 424 & & & & 0.2 \\
\hline Neg & & $283(97 \%)$ & $52(100 \%)$ & 74 (94\%) & \\
\hline Pos & & $10(3.4 \%)$ & $0(0 \%)$ & $5(6.3 \%)$ & \\
\hline Previous_myocardial_infarction & 424 & & & & 0.4 \\
\hline Neg & & 281 (96\%) & $52(100 \%)$ & 76 (96\%) & \\
\hline Pos & & $12(4.1 \%)$ & $0(0 \%)$ & $3(3.8 \%)$ & \\
\hline Previous_angioplasty & 424 & & & & 0.016 \\
\hline Neg & & $262(89 \%)$ & $52(100 \%)$ & 70 (89\%) & \\
\hline Pos & & 31 (II\%) & $0(0 \%)$ & $9(11 \%)$ & \\
\hline Previous_bypass_surgery & 9 & & & & \\
\hline Death & & $8(100 \%)$ & 0 (NA\%) & I (I00\%) & \\
\hline
\end{tabular}

(Continued) 
Table I (Continued).

\begin{tabular}{|c|c|c|c|c|c|}
\hline Characteristic & $\mathbf{n}$ & I I 5, n=293 & No $P C l, n=52$ & Personal, $\mathrm{n}=79$ & $p$-value \\
\hline Diagonal & 424 & & & & 0.6 \\
\hline Neg & & $284(97 \%)$ & $52(100 \%)$ & 77 (97\%) & \\
\hline Pos & & $9(3.1 \%)$ & $0(0 \%)$ & $2(2.5 \%)$ & \\
\hline LCX & 424 & & & & 0.016 \\
\hline Neg & & $263(90 \%)$ & $52(100 \%)$ & 67 (85\%) & \\
\hline Pos & & $30(10 \%)$ & 0 (0\%)- & 12 (I5\%) & \\
\hline OM & 424 & & & & 0.029 \\
\hline Neg & & $270(92 \%)$ & $52(100 \%)$ & 70 (89\%) & \\
\hline Pos & & $23(7.8 \%)$ & $0(0 \%)$ & 9 (II\%) & \\
\hline PDA & 424 & & & & 0.4 \\
\hline Neg & & $282(96 \%)$ & $52(100 \%)$ & $76(96 \%)$ & \\
\hline Pos & & II (3.8\%) & $0(0 \%)$ & $3(3.8 \%)$ & \\
\hline PLB & 424 & & & & $>0.9$ \\
\hline Neg & & 290 (99\%) & $52(100 \%)$ & 79 (100\%) & \\
\hline Pos & & $3(1.0 \%)$ & $0(0 \%)$ & $0(0 \%)$ & \\
\hline Left_main & 424 & & & & 0.5 \\
\hline Neg & & $292(100 \%)$ & $52(100 \%)$ & 78 (99\%) & \\
\hline Pos & & I (0.3\%) & $0(0 \%)$ & I (1.3\%) & \\
\hline Ramus & 424 & & & & 0.7 \\
\hline Neg & & $286(98 \%)$ & $52(100 \%)$ & 78 (99\%) & \\
\hline Pos & & 7 (2.4\%) & 0 (0-\%) & I (I.3\%) & \\
\hline RCA & 424 & & & & $<0.001$ \\
\hline Neg & & $190(65 \%)$ & $52(100 \%)$ & 61 (77\%) & \\
\hline Pos & & $103(35 \%)$ & $0(0 \%)$ & $18(23 \%)$ & \\
\hline LAD & 424 & & & & $<0.001$ \\
\hline Neg & & I 42 (48\%) & $52(100 \%)$ & $36(46 \%)$ & \\
\hline Pos & & $15 \mid(52 \%)$ & $0(0 \%)$ & 43 (54\%) & \\
\hline SVD & 424 & & & & $<0.001$ \\
\hline Neg & & 219 (75\%) & $52(100 \%)$ & $65(82 \%)$ & \\
\hline Pos & & 74 (25\%) & $0(0 \%)$ & 14 (I8\%) & \\
\hline 2VD & 424 & & & & $<0.001$ \\
\hline Neg & & 195 (67\%) & $52(100 \%)$ & $46(58 \%)$ & \\
\hline Pos & & 98 (33\%) & $0(0 \%)$ & $33(42 \%)$ & \\
\hline 3VD & 424 & & & & $<0.001$ \\
\hline Neg & & $182(62 \%)$ & $52(100 \%)$ & $49(62 \%)$ & \\
\hline Pos & & III (38\%) & $0(0 \%)$ & $30(38 \%)$ & \\
\hline$H B$ & 424 & & & & $>0.9$ \\
\hline Neg & & 291 (99\%) & $52(100 \%)$ & $79(100 \%)$ & \\
\hline Pos & & $2(0.7 \%)$ & $0(0 \%)$ & $0(0 \%)$ & \\
\hline Anterior myocardial infarction & 275 & & & & 0.5 \\
\hline Neg & & $10 \mid(5 \mid \%)$ & 0 (NA\%) & $43(57 \%)$ & \\
\hline Pos & & 98 (49\%) & 0 (NA\%) & $33(43 \%)$ & \\
\hline
\end{tabular}


Table I (Continued).

\begin{tabular}{|l|l|l|l|l|l|}
\hline Characteristic & $\mathbf{n}$ & $\mathbf{I ~ I 5 , ~} \mathbf{n = 2 9 3}$ & No PCI, $\mathbf{n = 5 2}$ & Personal, $\mathbf{n = 7 9}$ & $\boldsymbol{p}$-value \\
\hline Systolic blood pressure, $\mathrm{mmHg}$ & $35 \mathrm{I}$ & $124.46(20.72)$ & NA (NA) & $124.73(18.50)$ & 0.9 \\
Diastolic blood pressure, $\mathrm{mmHg}$ & 147 & $79.85(14.6 \mathrm{I})$ & NA (NA) & $79.95(12.5 \mathrm{I})$ & 0.8 \\
Heart rate, beats/min & 349 & $79.45(15.26)$ & NA (NA) & $82.97(12.28)$ & 0.017 \\
Creatinine clearance, $\mathrm{mL} / \mathrm{min}$ & $29 \mathrm{I}$ & $1.42(0.78)$ & NA (NA) & $1.58(\mathrm{I}) .14)$ & $>0.9$ \\
\hline
\end{tabular}

Table 2 Comparison LVEF in Different Groups

\begin{tabular}{|l|l|l|l|l|l|}
\hline Characteristic & $\mathbf{n}$ & $\begin{array}{l}\mathbf{1 1 5}, \\
\mathbf{n = 2 9 3}\end{array}$ & $\begin{array}{l}\text { No } \\
\mathbf{P C l}, \\
\mathbf{n = 5 2}\end{array}$ & $\begin{array}{l}\text { Personal, } \\
\mathbf{n = 7 9}\end{array}$ & $\mathbf{p}$-value \\
\hline LVEF (\%) & 294 & $\begin{array}{l}39.84 \\
(11.22)\end{array}$ & $\begin{array}{l}\text { NA } \\
\text { (NA) }\end{array}$ & $\begin{array}{l}36.58 \\
(10.83)\end{array}$ & 0.019 \\
\hline
\end{tabular}

Table 3 Comparison Door-to-balloon in Different Groups

\begin{tabular}{|l|l|l|l|l|l|}
\hline Characteristic & $\mathbf{n}$ & $\begin{array}{l}\mathbf{I I 5} \\
\mathbf{n = 2 9 3}\end{array}$ & $\begin{array}{l}\text { No } \\
\mathbf{P C l}, \\
\mathbf{n = 5 2}\end{array}$ & $\begin{array}{l}\text { Personal, } \\
\mathbf{n = 7 9}\end{array}$ & P-value \\
\hline $\begin{array}{l}\text { Door to balloon } \\
\text { time (min) }\end{array}$ & 296 & $\begin{array}{l}57.78 \\
(127.74)\end{array}$ & $\begin{array}{l}\text { NA } \\
\text { (NA) }\end{array}$ & $\begin{array}{l}141.70 \\
(237.64)\end{array}$ & $<0.001$ \\
\hline
\end{tabular}

the time of angioplasty did not differ significantly between groups, $p=0.074$.

Door-to-balloon time was significantly less in group C compared to group A, $p<0.001$, Table 3 .

\section{Discussion}

The aim of this study was to evaluate the mortality rate among STEMI patients who were provided emergency service and were referred for coronary angioplasty. The results of our study showed that the mortality rate among the patients who were provided emergency service and those who were not, did not differ significantly. Prehospital ECG is associated with reduced reperfusion time, and the diagnosis of STEMI by paramedic staff. In addition, it is associated with reduced mortality and better hospitalization outcomes. ${ }^{14}$ Timely referral of these patients directly to PPCI centers, compared to those who are indirectly transferred, can reduce mortality rate significantly by most likely effecting call-to-balloon time. ${ }^{15} \mathrm{An}$ increase in ECG-to-decision time for PCI also increases the risk of 30-day mortality among STEMI patients. ${ }^{16}$ Transmission of ECG by paramedic staff to emergency physician increases the odds of positive prediction of
STEMI and eases the decision-making process. ${ }^{17}$ A recent study reported that prehospital diagnosis can also provide data regarding pathologic Q wave in STEMI patients, which is associated with a risk of mortality and adverse outcomes. ${ }^{18}$ Prehospital factors can increase the time to PCI, which is associated with increased mortality. ${ }^{19}$

The results of our study indicated that indirect referral and emergency referral had a difference in in-hospital, sixmonths, one, and three-year mortality rates in STEMI patients, however, the difference was not statistically significant. Patients who were referred to our PPCI center via emergency service had a significantly lower door-toballoon time. The findings of our study are in parallel with those provided by Savage et al. ${ }^{20}$ The study reported that prehospital diagnosis of STEMI was associated with a decrease in door-to-balloon time and a statistically nonsignificant reduction in one and six-month mortality rates. The outcomes from the study by Yeoh et al also reported that prehospital diagnosis and notification for STEMI can reduce door-to-balloon time, nonetheless, it may not influence short-term mortality rates. ${ }^{21}$

A meta-analysis by Nam et $\mathrm{al}^{22}$ concluded that prehospital ECG diagnosis is associated with a reduction in short-term mortality along with first medical contact-toballoon, door-to-balloon, and door-to-needle time. A study by Chan et $\mathrm{al}^{23}$ conducted on 167 patients referred to the PCI center with prehospital triage and 427 patients admitted by inter-hospital transfer, 90-min door-toballoon time was greater in prehospital triage group along with postprocedural thrombolysis. In addition, 30 days and one-year mortality were also significantly lower in this group, therefore, prehospital triage was concluded to improve survival rates. Similarly, Jerónimo Sousa et al ${ }^{24}$ reported that first medical contact to ECG was associated with the best performance. Prehospital emergency patient service significantly reduces ischemic time and ECG-toPCI, ECG-to-balloon center time. Nonetheless, short FMC-to-device time $<90 \mathrm{~min}$ is dependent on the distance 
to the PCI center and the use of protocol-driven EMS ground transportation. ${ }^{25}$ In another retrospective study by Farshid et al, ${ }^{26}$ prehospital Cath Lab examination significantly reduced ischemic time and 12-month mortality rate compared to emergency department examination among STEMI patients. The study concluded that ischemic time and mortality rate can be reduced, as a result of prehospital diagnosis, by greater than $50 \%$. Compared to these studies, the outcomes from our study do not differ significantly. These discrepancies can be the result of sample sizes in the two groups (emergency and nonemergency referral), the expertise for paramedic staffs in the diagnosis of STEMI, PPCI-expert skills, difference in the protocols and other health-associated factors. A wide range of variations among the outcomes of STEMI patients have been reported globally as a result of hospital care, clinical profile and mortality. ${ }^{27}$ Moreover, our study does not include other cardiovascular parameters such as hyperlipidemia that can increase the risk of mortality among these patients. Distance and availability of PCI center have not been considered in this study, as well. Our study included a greater number of male patients and mortality following PCI in STEMI patients might be influenced based on gender. $^{28}$ Overall, a significant reduction in door-toballoon time and nonsignificant reduction in mortality rate among emergency and nonemergency service referral of patients to our PCI center suggest that prehospital triage can improve intrahospital and posthospital outcomes in STEMI patients.

\section{Human and Animal Rights}

No animals were used in this research. All human research procedures followed were approved and were in accordance with the ethical standards of the committee responsible for human experimentation (Tehran University of Medical Sciences), and with the Declaration of Helsinki 1975 , revised in 2013.

\section{Data Sharing Statement}

Data sharing is not applicable to this article as no datasets were generated or analyzed during the current study.

\section{Consent for Publication}

Informed consent was obtained from each participant.

\section{Author Contributions}

ZA and RA conceptualized and designed the study, drafted the initial manuscript, and reviewed and revised the manuscript. MS and PH designed the data collection instruments, collected data, carried out the initial analyses, and reviewed and revised the manuscript. PS coordinated and supervised data collection, and critically reviewed the manuscript for important intellectual content. All authors made substantial contributions to conception and design, acquisition of data, or analysis and interpretation of data; took part in drafting the article or revising it critically for important intellectual content; agreed to submit to the current journal; gave final approval of the version to be published; and agree to be accountable for all aspects of the work.

\section{Disclosure}

The authors report no conflicts of interest in this work.

\section{References}

1. Scholz KH, Maier SKG, Maier LS, et al. Impact of treatment delay on mortality in ST-segment elevation myocardial infarction (STEMI) patients presenting with and without haemodynamic instability: results from the German prospective, multicentre FITT-STEMI trial. Eur Heart J. 2018;39(13):1065-1074. doi:10.1093/eurheartj/ehy004

2. Shiyovich A, Bental T, Plakht Y, et al. Prediction of mortality in hospital survivors of STEMI: external validation of a novel acute myocardial infarction prognostic score. Cardiovasc Revasc Med. 2019;20(2):96-100. doi:10.1016/j.carrev.2018.05.008

3. Hayıroğlu M, Keskin M, Uzun AO, et al. Predictive value of SYNTAX score II for clinical outcomes in cardiogenic shock underwent primary percutaneous coronary intervention; a pilot study. Int $J$ Cardiovasc Imaging. 2018;34(3):329-336. doi:10.1007/ s10554-017-1241-9

4. Mello B, Oliveira GBF, Ramos RF, et al. Validation of the Killip-Kimball classification and late mortality after acute myocardial infarction. Arq Bras Cardiol. 2014;103(2):107-117. doi:10.5935/ abc. 20140091

5. DeGeare V, Boura J, Grines L, O’Neill W, Grines C. Predictive value of the Killip classification in patients undergoing primary percutaneous coronary intervention for acute myocardial infarction. $\mathrm{Am}$ J Cardiol. 2001;87:1035-1038. doi:10.1016/S0002-9149(01)01457-6

6. Hayıroğlu M, Keskin M, Uzun AO, et al. Predictors of in-hospital mortality in patients with ST-segment elevation myocardial infarction complicated with cardiogenic shock. Heart Lung Circ. 2019;28 (2):237-244. doi:10.1016/j.hlc.2017.10.023

7. de Lemos JA, Ettinger SM. 2013 ACCF/AHA guideline for the management of ST-elevation myocardial infarction. $J$ Am Coll Cardiol. 2013;61(4).

8. McNamara RL, Wang Y, Herrin J, et al. Effect of door-to-balloon time on mortality in patients with ST-segment elevation myocardial infarction. J Am Coll Cardiol. 2006;47(11):2180-2186. doi:10.1016/ j.jacc.2005.12.072

9. De Luca G, Suryapranata H, Ottervanger JP, Antman EM. Time delay to treatment and mortality in primary angioplasty for acute myocardial infarction: every minute of delay counts. Circulation. 2004;109 (10):1223-1225. doi:10.1161/01.CIR.0000121424.76486.20

10. Kahlon TS, Barn K, Akram MMA, et al. Impact of pre-hospital electrocardiograms on time to treatment and one year outcome in a rural regional ST-segment elevation myocardial infarction network. Catheter Cardiovasc Interv. 2017;89(2):245-251. doi:10.1002/ ccd.26567 
11. Ibanez B, James S, Agewall S, et al. 2017 ESC Guidelines for the management of acute myocardial infarction in patients presenting with ST-segment elevation: the Task Force for the management of acute myocardial infarction in patients presenting with ST-segment elevation of the European Society of Cardiology (ESC). Eur Heart J. 2017;39(2):119-177.

12. Welsh RC, Travers A, Huynh T, Cantor WJ. Canadian Cardiovascular Society Working Group: providing a perspective on the 2007 focused update of the American College of Cardiology and American Heart Association 2004 guidelines for the management of ST elevation myocardial infarction. Can J Cardiol. 2009;25(1):25-32. doi:10.10 16/S0828-282X(09)70019-4

13. Benamer H, Bataille S, Tafflet $\mathrm{M}$, et al. Longer pre-hospital delays and higher mortality in women with STEMI: the e-MUST registry. EuroIntervention. 2016;12(5):e542-549. doi:10.4244/EIJV12I5A93

14. Le May MR, Dionne R, Maloney J, Poirier P. The role of paramedics in a primary PCI program for ST-elevation myocardial infarction. Prog Cardiovasc Dis. 2010;53(3):183-187. doi:10.1016/j.pcad.2010. 08.003

15. Rathod KS, Koganti S, Jain A, et al. P6452Inter-hospital transfer for primary PCI has worse outcome compared with direct admission to a heart attack centre: observational study of 25,315 patients with STEMI from the London heart attack group. Eur Heart J. 2018;39 (suppl_1). doi:10.1093/eurheartj/ehw180.

16. Mullvain R, Saman DM, Rostvedt A, Landgren P. ECG-to-decision time impact on 30-day mortality and reperfusion times for STEMI care. Crit Pathw Cardiol. 2018;17(1):19-24. doi:10.1097/HPC.0000 000000000130

17. Davis DP, Graydon C, Stein R, et al. The positive predictive value of paramedic versus emergency physician interpretation of the prehospital 12-lead electrocardiogram. Prehosp Emerg Care. 2007;11 (4):399-402. doi:10.1080/10903120701536784

18. Meloni L, Marchetti MF, Cacace C, et al. Prognosis and first diagnostic ECG in STEMI patients referred to the emergency medical system for primary PCI. J Electrocardiol. 2018;51(6):1131-1134. doi:10.1016/j.jelectrocard.2018.09.003

19. Studnek JR, Infinger A, Wilson $H$, Niess $G$, Jackson $P$, Swanson D. Decreased time from 9-1-1 call to pci among patients experiencing stemi results in a decreased one year mortality. Prehosp Emerg Care. 2018;22(6):669-675. doi:10.1080/10903127. 2018.1447621
20. Savage ML, Poon KKC, Johnston EM, et al. Pre-hospital ambulance notification and initiation of treatment of ST elevation myocardial infarction is associated with significant reduction in door-to-balloon time for primary PCI. Heart Lung Circ. 2014;23(5):435-443. doi:10.1016/j.hlc.2013.11.015

21. Yeoh J, Andrianopoulos N, Brennan A, et al. Pre-hospital ambulance notification for ST elevation myocardial infarction (STEMI) leads to rapid reperfusion but no effect on early mortality: insights from the Melbourne Interventional Group (MIG) registry. Heart Lung Circ. 2017;26:S229. doi:10.1016/j.hlc.2017.06.426

22. Nam J, Caners K, Bowen JM, Welsford M, O’Reilly D. Systematic review and meta-analysis of the benefits of out-of-hospital 12-lead ECG and advance notification in ST-segment elevation myocardial infarction patients. Ann Emerg Med. 2014;64(2):176-86.e9. doi:10.1016/j.annemergmed.2013.11.016

23. Chan AW, Kornder J, Elliott H, et al. Improved survival associated with pre-hospital triage strategy in a large regional ST-segment elevation myocardial infarction program. JACC Cardiovasc Interv. 2012;5(12):1239-1246. doi:10.1016/j.jcin.2012.07.013

24. Jerónimo Sousa P, Campante Teles R, Brito J, et al. Primary PCI in ST-elevation myocardial infarction: mode of referral and time to PCI. Rev Port Cardiol. 2012;31(10):641-646. doi:10.1016/j.repce.2012. 08.001

25. Bennin C-LK, Ibrahim S, Al-Saffar F, Box LC, Strom JA. Achieving timely percutaneous reperfusion for rural ST-elevation myocardial infarction patients by direct transport to an urban PCI-hospital. $J$ Geriatr Cardiol. 2016;13(10):840-845. doi:10.11909/j.issn.16715411.2016.10.012

26. Farshid A, Allada C, Chandrasekhar J, et al. Shorter ischaemic time and improved survival with pre-hospital STEMI diagnosis and direct transfer for primary PCI. Heart Lung Circ. 2015;24(3):234-240. doi:10.1016/j.hlc.2014.09.015

27. Rosselló X, Huo Y, Pocock S, et al. Global geographical variations in ST-segment elevation myocardial infarction management and post-discharge mortality. Int J Cardiol. 2017;245:27-34. doi:10. 1016/j.ijcard.2017.07.039

28. Siabani S, Davidson PM, Babakhani M, et al. Gender-based difference in early mortality among patients with ST-segment elevation myocardial infarction: insights from Kermanshah STEMI registry. $J$ Cardiovasc Thorac Res. 2020;12(1):63-68. doi:10.34172/jcvtr.20 20.10
International Journal of General Medicine

\section{Publish your work in this journal}

The International Journal of General Medicine is an international, peer-reviewed open-access journal that focuses on general and internal medicine, pathogenesis, epidemiology, diagnosis, monitoring and treatment protocols. The journal is characterized by the rapid reporting of reviews, original research and clinical studies across all disease areas. The manuscript management system is completely online and includes a very quick and fair peer-review system, which is all easy to use. Visit http://www.dovepress.com/ testimonials.php to read real quotes from published authors. 